
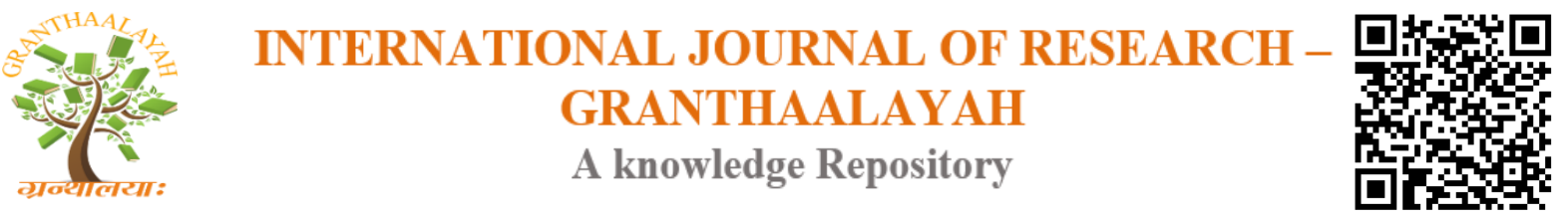

Science

\title{
FARM EFFICIENCY MEASUREMENT OF PADDY PRODUCTION IN NORTHERN SRI LANKA USING DATA ENVELOPMENT ANALYSIS (DEA) APPROACH
}

\author{
Ponniah Sivarajah ${ }^{* 1}$ \\ ${ }^{* 1}$ Department of Agricultural Economics, Faculty of Agriculture, Eastern University, \\ Chenkalady, Sri Lanka
}

\begin{abstract}
This study analyzed the production efficiency of paddy farms in Northern Sri Lanka using the Data Envelopment Analysis approach (DEA). Farm efficiency has been related to resource use efficiency and achievement of higher productivity. The aim of this study was to study the levels of production efficiency of small paddy farms, and to identify the impacts of land size and extension worker contacts on production efficiency. A total of 120 farmers were randomly selected in the Mannar district in Northern Sri Lanka. The DEA technique was used to measure technical/production efficiency and results were compared for land size and extension contact category of farmers. It was found that more than average of farms had low efficiency scores of below 0.5. Small farms and large farms had a significant difference in efficiency scores. Thus this indicates that there is an impact of land size on farm production efficiency and very small farms and also large farms are inefficient in paddy production the area. There was a significant difference in farm efficiency between farmers with extension contacts and otherwise. The study reinforced the role that can be played by extension workers in pushing the farm efficiency levels higher and helping in better resource use efficiency on farms.
\end{abstract}

Keywords: DEA; Extension Contacts; Land Size; Paddy; Production Efficiency; Resource Use.

Cite This Article: Ponniah Sivarajah. (2017). "FARM EFFICIENCY MEASUREMENT OF PADDY PRODUCTION IN NORTHERN SRI LANKA USING DATA ENVELOPMENT ANALYSIS (DEA) APPROACH." International Journal of Research - Granthaalayah, 5(9), 164-170. https://doi.org/10.29121/granthaalayah.v5.i9.2017.2226.

\section{Introduction}

Production efficiency is an approach to ensure that products of firms are produced in the most profitable manner. To prevent waste of resources, efficiency is of great importance for every sector in the economy. The most popular techniques used to measure farm efficiency are the Data Envelopment Analysis (DEA) (Charnes et al. 1978) and the Stochastic Frontier Analysis (SFA) (Aigner et al. 1977; Meeusen and van den Broeck, 1977). The former uses mathematical linear programming methods, whereas the latter uses econometric methods. The quality of the 
data, the appropriateness of various functional forms, and the possibility of making behavioural assumptions will heavily influence the relative appropriateness of DEA.

The DEA approach does not require any specific functional form to be selected, neither are any behavioural assumptions needed as long as allocative efficiency is not considered. However, DEA is a deterministic approach, thus it doesn't account for noise in the data. All deviations from the frontier will thus be accounted for as inefficiencies. Therefore the DEA efficiency scores are likely to be sensitive to measurements errors and random errors (Coelli et al, 2002).

Lansink et al (2002) studied technical efficiency of Finnish farms using the Data Envelopment Analysis (DEA), and found that the conventional livestock farms had technical efficiency scores of 69\%. Jonasson (1996) measured various output efficiencies of a sample of Swedish farms using DEA and found that the average technical and allocative output efficiencies were 0.95 and 0.92 respectively. Adding an extra output or input in DEA will never cause a reduction of the efficiency scores and a greater number of outputs and inputs compared to the total number of observations will always cause greater efficiency scores (Coelli et al, 2002).

Farm size is a parameter which has shown a significant influence on efficiency. Bravo-Ureta and Rieger (1991) found a significant positive relationship between technical efficiency and farm size in the sample of New England dairy farms. However, the relationship between economic efficiency and allocative efficiency and size was found to be significantly negative. Bailey et al. (1989), who estimated technical, allocative and economic efficiency on Ecuadorian dairy farms, also found a positive relationship between land size and technical efficiency. Sharma et al (1999) studied swine producers in Hawaii and estimated technical and economic efficiencies using the DEA approach under the assumption of constant returns to scale (CRS) and variable returns to scale (VRS).

The aim of the present paper is to use the DEA method in estimating technical efficiency in paddy production in Northern Sri Lanka in order to measure the resource use efficiency. Considering the changing structure and market situation of these small paddy farms $(<1$ to 5 acres), studies of the economic input efficiency is of high importance to understand the challenges facing the paddy farmers on small landholdings.

\section{Materials and Methods}

The idea behind efficiency studies is to measure a firm's position relative to an efficient frontier, resulting in an efficiency score of the firm. The efficiency scores will be bounded between zero and one, where a score of one indicates full efficiency. Measurement of efficiency requires knowledge of the efficient production function, which has to be estimated from the sample farm data.

The data used in the study are based on the primary data collected from randomly selected farm households pertained to the agricultural year 2012. A total of 120 farmers from 4 villages, 30 farmers from each, were randomly selected in the Mannar district in Northern Sri Lanka. The selected villages were Nanattan, Alayadivembu, Murukkan and Uyilankulam. These are mainly paddy producing areas and have a similar topography and soil type. Detailed information 
pertaining to inputs such as seed, fertilizer, labour, manure and yield of paddy and other socioeconomic characteristics of farmers were collected.

Managerial decisions concerning what to produce and which input-mix to use are intended to achieve target objectives. When input prices are involved, producers are assumed to allocate resources efficiently by using the combination of inputs that minimises the cost of producing a level of output. Charnes et al. (1978) introduced DEA techniques that used mathematical programming to pursue Farrell's approach to technical efficiency measurement (see Farrell, 1957). They developed a method to deal with the case of multiple outputs and multiple inputs. This goal was achieved by computing a maximal performance measure for each production unit relative to all other units in the sample. For each inefficient production unit, a measure of relative inefficiency can be calculated by comparing its observed behaviour with the behaviour of a reference unit located on the technological frontier.

Efficiency is measured relative to this frontier, where all deviations from the frontier are assumed to be inefficiency. DEA is a linear programming based technique for measuring the relative performance of Decision Making Units (DMU) where the presence of multiple inputs and outputs. Later Charnes, Cooper and Rhodes (CCR) were the proponents of DEA and formulated a fractional programming problem called DEA Ratio Model (Charnes et al., 1978) which was depicted as follows:

Maximize: $\quad \mathbf{E}_{\mathbf{m}}=\frac{\sum_{j=1}^{J} U_{j m} Y_{j m}}{\sum_{i=1}^{I} V_{i m} X_{i m}}$

Subject to $\frac{\sum_{j=1}^{J} U_{j m} Y_{j n}}{\sum_{i=1}^{I} V_{i m} X_{i n}} \leq 1, n=1 \ldots N$

Where: $U_{j m}, V_{i m} \geq 0 \quad i=1,2, \ldots \ldots I: j=1,2, \ldots \ldots . . J$

$$
\begin{aligned}
& E_{m}=\text { the efficiency of the } m^{\text {th }} D M U, \\
& Y_{j m}=j^{\text {th }} \text { output of the } m^{\text {th }} D M U, \\
& U_{j m}=\text { the weight of that output, } \\
& X_{i m}=i^{\text {th }} \text { input of the } m^{\text {th }} \text { DMU, } \\
& V_{i m}=\text { the weight of that output, } \\
& Y_{j n} \text { and } X_{i n} \text { are } j^{\text {th }} \text { output and } i^{\text {th }} \text { input, respectively of the } n^{\text {th }} D M U, n=1,2, \ldots . . N \text {. }
\end{aligned}
$$

Here $n$ includes $m$. 
In the solution to this model the efficiency of $\mathrm{m}^{\text {th }}$ unit is maximized subject to efficiencies of all units in the set having an upper bound of 1. The key feature of the above model is that the weights $U_{j m}$ and $V_{i m}$ are treated as unknown. They will be chosen so as to maximize the efficiency of $\mathrm{m}^{\text {th }}$ target unit. The efficiency of $\mathrm{m}^{\text {th }}$ target unit will either equal to 1 in which case it is efficient relative to other units or will be less than 1 in which case the unit is inefficient. The data envelopment analysis program (DEAP Ver.2.1) developed by Coelli,T.J (1996) was used for data analysis.

Many studies had used of DEA techniques in analyzing efficiency issues in agriculture. PiotLepetit et al. (1997) employed non-parametric analysis to deal with environmental externalities in French agriculture. Ir.Aizoz et al. (2003) also used non-parametric techniques to assess the efficiency of horticultural production in Spain, while Reig-Martınez and Picazo-Tadeo (2004) used DEA to measure efficiency of citrus farms in Spain. Other related studies are Llewelyn and Williams (1996), Fraser and Cordina (1999), Wadud and White (2000) and Shaficq and Rehman (2000). Technical and cost efficiencies of smallholder coffee farms in Vietnam was analyzed by Rios and Shively (2005) using DEA method.

The main contribution of this paper is that it explores the use of DEA to assess the technical efficiency of small paddy farms in Northern Sri Lanka, and assess the effect of land size and extension contacts on production efficiency.

\section{Results And Discussions}

The analysis showed that about $45 \%$ of farms studied were less than 5 acres ( 2 ha) in size, thus small farms. The mean efficiency of farms studied was 0.558 . It was also observed that $60 \%$ of farms had low efficiency scores ( 0 t0 0.6 ), about $15 \%$ farms had medium efficiency scores (above 0.6 to 0.8 ), while $25 \%$ of the farms had high efficiency scores (greater than 0.8 ). Thus the results indicate that around $75 \%$ of farms were inefficient in paddy production and thus there is a need to enhance their production efficiency through the use of better management practices or improved farm technology.

Table 1: Mean of Efficiency measures and efficiency classes of farms

\begin{tabular}{|c|l|}
\hline Measurements & Efficiency level \\
\hline 1. Mean Efficiency $(\mathbf{n}=\mathbf{1 2 0})$ & $\mathbf{0 . 5 5 8}$ \\
\hline 2. Efficiency Classes & Frequency $(\boldsymbol{\%})$ \\
\hline a. $\underline{\text { Low }}(0$ to 0.5$)$ & $\mathbf{7 2}(\mathbf{6 0})$ \\
$(>0.5$ to 0.6$)$ & 67 \\
b. $\underline{\text { Medium }}(>0.6$ to 0.7$)$ & 05 \\
$(>0.7$ to 0.8$)$ & $\mathbf{1 8}(\mathbf{1 5})$ \\
c. $\underline{\text { High }}(>0.8$ to 0.9$)$ & 11 \\
$(>0.9$ to 1.0$)$ & 07 \\
Total & $\mathbf{3 0}(\mathbf{2 5})$ \\
& 24 \\
\hline & $\mathbf{1 2 0}(\mathbf{1 0 0})$ \\
\hline
\end{tabular}


Also 20\% (24 farms) had an efficiency score greater than 0.9 and were producing close to the efficient frontier, implying that they were using resources more efficiently than other farms. Field observations had shown that there was a low level of input use and also poor management practices on small farms. These could have been the reasons for the low efficiency scores of many farms in the area. It was also found that there were significant differences $(\mathrm{P}<0.05)$ in efficiency levels between small farms ( $<5$ acres size), large farms ( $>15$ acres size) and medium farms (>5-15 acres size).

Table 2: Efficiency measures for different farm size categories

\begin{tabular}{|l|l|}
\hline Farm Size classes & Mean Efficiency \\
\hline 1. $[1$ to 5 acs] $(\mathrm{n}=45)$ & $0.599^{\mathrm{a}}$ \\
\hline 2. $[6$ to 10 acs $)(\mathrm{n}=32)$ & $0.741^{\mathrm{b}}$ \\
\hline 3. $[11$ to 15 acs] $(\mathrm{n}=11)$ & $0.804^{\mathrm{b}}$ \\
\hline 4. [above 15 acs] $(\mathrm{n}=12)$ & $0.601^{\mathrm{a}}$ \\
\hline
\end{tabular}

*-Figures with similar letters are not significantly different at $\mathrm{P}<5 \%$ level.

The analysis on whether different farm sizes had an effect on farm efficiency levels showed that small farms ( $<5$ acres) and large farms $(>15$ acres) had a significant difference $(\mathrm{P}<0.05)$ in efficiency scores. The results indicated that paddy farms of land extents ranging from 1 to 5 acres and greater than 15 acres had an efficiency score of 0.599 to 0.601 ; whereas farms with a land extent of 6 to 15 acres had an efficiency score ranging from 0.741 to 0.8 . Thus farms of moderate land size were found to be more efficient in production compared to small farms $(<5$ acres) and large farms (>15 acres). Thus this indicates that there is an impact of land size on farm efficiency and very small farms and also large farms are inefficient in paddy production the area. These results are comparable to findings of Reig-Martinez \& Picazo-Tadeo (2004) on analysis of citrus farms for profit efficiency which indicated small farms (29\%) being production inefficient. Similar findings were obtained by Rios \& Shively (2005) in a study of coffee farms in Vietnam found small farms to be inefficient compared to large farms.

Table 3: Extension Contact and Farm Efficiency distribution -DEA measure

\begin{tabular}{|l|l|l|}
\hline \multirow{2}{*}{ Efficiency Level } & Extension Contact \\
\cline { 2 - 3 } & Have Contact & No Contact \\
\hline 1. Mean Efficiency & 0.817 & 0.325 \\
\hline $\begin{array}{l}\text { 2. Efficiency Classes } \\
\text { a. } \text { Low }\end{array}$ & Numbers (\%) & Numbers (\%) \\
\cline { 2 - 3 }$(0$ to 0.5$)$ & $07(11.67)$ & $33(82.5)$ \\
$(>0.5$ to 0.6$)$ & $05(8.33)$ & $01(2.5)$ \\
b. Medium & & $03(7.5)$ \\
$(>0.6$ to 0.7$)$ & $02(3.33)$ & $00(0.0)$ \\
$(>0.7$ to 0.8$)$ & $06(10.0)$ & $00(0.0)$ \\
c. High & & $03(7.5)$ \\
$(>0.8$ to 0.9$)$ & $09(15.0)$ & $40(100.0)$ \\
$(>0.9$ to 1.0$)$ & $31(51.67)$ & \\
\hline Total & $60(100.0)$ & \\
\hline
\end{tabular}


The analysis on whether extension worker contacts had an impact on farm efficiency, it was observed that those farmers who had contacts with extension workers had a significantly $(\mathrm{P}<0.05)$ higher farm efficiency score $(0.817)$ than those with no contacts $(0.325)$. This implied that extension contacts had a strong influence on farm efficiency level achieved by farmers. It was also observed that among those farmers with extension worker contacts about $51.7 \%$ of them had achieved efficiency levels beyond 0.9 , which reinforces the role that can be played by extension workers in pushing the farm efficiency levels to a higher frontier. Bhatta et al. (2006) in a study of small Nepalese farms revealed that agricultural extension services have a positive and significant contribution, and it increases technical efficiency of the farm.

\section{Conclusions and Recommendations}

It was found that more than average of farms had low efficiency scores of below 0.5. Small farms and large farms had a significant difference in efficiency scores. Thus this indicates that there is an impact of land size on farm efficiency and very small farms and also large farms are inefficient in paddy production the area. There was a significant difference in farm efficiency between farmers with extension contacts and otherwise. The study reinforced the role that can be played by extension workers in pushing the farm efficiency levels higher and helping in better resource use efficiency on farms. Thus policies that focus on land augmentation and increasing extension workers numbers could help raise farm efficiency levels on farms in Northern Sri Lanka through better extension services advice and technology transfer.

\section{References}

[1] Aigner, D., Lovell, C. A. X., and Schmidt, P. (1977). Formulation and Estimation of Stochastic Frontier Production Function Models. Journal of Econometrics. 6: 21-37.

[2] Bailey, D., Biswas, B, Kumbhakar, S. C., and Schulthies, B. K. (1989). An Analysis of Technical, Allocative, and Scale Inefficiency: The Case of Ecuadorian Dairy Farms. Western Journal of Agricultural Economics. 14: 30-37.

[3] Bhatta, Kiran Prasad and Ishida, Akira and Taniguchi, Kenji and Sharma, Raksha (2006): Technical Efficiency of Rural Nepalese Farmers as Affected by Farm Family Education and Extension Services. Journal of Rural Economics, Vol. 2006, No. Special Issue (1 December 2006): pp. 316-323.

[4] Bravo-Ureta, B. and Rieger, L. (1991). Dairy Farm Efficiency Measurement Using Stochastic Frontiers and Neoclassical Duality. American Journal of Agricultural Economics. 73: 421-428.

[5] Charnes, A., Cooper, W. W., and Rhodes, E., (1978). Measuring the Efficiency of Decision Making Units. European Journal of Operational Research. 2: 429-444.

[6] Coelli, T., Rao, P. D. S., and Battese, G. E. (2002). An Introduction to Efficiency and Productivity Analysis. Kluwer Academic Publishers, London.

[7] Coelli, T. J. (1996). A Guide to DEAP Version 2.1: A data envelopment analysis (computer) program. Center for Efficiency and Productivity Analysis (CEPA) Working paper 96/08. Department of Econometrics. New England University, Armidale, Australia.

[8] Farrel, M. J. (1957). The Measurement of Productive Efficiency. Journal of the Royal Statistical Society. Ser. A 120: 253-281.

[9] Fraser, I., Cordina, D. (1999). An application of data envelopment analysis to irrigated dairy farms in Northern Victoria, Australia. Agricultural Systems 59, 267-282.

[10] Iráizoz, B., Rapún, M., Zabaleta, I. (2003). Assessing the technical efficiency of horticultural production in Navarra, Spain. Agricultural Systems 78: 387-403 
[11] Jonasson, L., (1996). Mathematical programming for sector analysis - some applications, evaluations and methodological proposals. Dissertations. Swedish University of Agricultural Sciences, Department of Economics.

[12] Lansink O. A., Pietola, K. and Bäckman, S. (2002) Efficiency and productivity of conventional and organic farms in Finland 1994-1997. European Review of Agricultural Economics. 29: 51-65

[13] Llewelyn, R.V., Williams, J.R. (1996). Nonparametric analysis of technical, pure technical and scale efficiency for food crop production in East Java, Indonesia. Agricultural Economics 15, 113-126.

[14] Meeusen, W. and van den Broeck, J. (1977). Efficiency Estimation from Cobb-Douglas production functions with composed errors. International Economic Review. 18: 435-444

[15] Piot-Lepetit, I., Vermerschd, D., Weaver, R.D. (1997). Agriculture's environmental externalities: DEA evidence for French agriculture. Applied Economics 29, 331-338.

[16] Reig-Martınez,E., A.J. Picazo-Tadeo (2004). Analysing farming systems with Data Envelopment Analysis: citrus farming in Spain. Agricultural Systems 82, 17-30.

[17] Rios, Ana R., G.E.Shively (2005). Farm size and nonparametric efficiency measurements for coffee farms in Vietnam. Paper presentation at the American Agricultural Economics Association Annual Meeting, Providence, Rhode Island, July 24-27, 2005.

[18] Shaficq, M., Rehman, T. (2000). The extent of resource use inefficiencies in cotton production in Pakistan's Punjab: an application of Data Envelopment Analysis. Agricultural Economics 22, 321-330.

[19] Sharma, K. R, Leung, P., Zaleski, H. M. (1999). Technical, allocative and economic efficiencies in swine production in Hawaii: a comparison of parametric and nonparametric approaches. Agricultural Economics. 20: 23-35

[20] Wadud, A., White, B. (2000). Farm household efficiency in Bangladesh: a comparison of stochastic frontier and DEA methods. Applied Economics 32, 1665-1673.

*Corresponding author.

E-mail address: sivaponniah@ yahoo.com 